\title{
Discussion on the Cultivation of Scientific Research Ability of Postgraduates Majoring in Medicine
}

\author{
Liang Liang* \\ Department of ophthalmology, Yichang central hospital, China \\ *Corresponding author: Liang Liang, Department of ophthalmology, Yichang central hospital, Yichang city, China
}

ARTICLE INFO

Received: 幽 November 07, 2019

Published: 慧 November 12, 2019

Citation: Liang Liang. Discussion on the Cultivation of Scientific Research Ability of Postgraduates Majoring in Medicine. Biomed J Sci \& Tech Res 22(4)-2019. BJSTR. MS.ID.003793.

\begin{abstract}
In order to further promote the development of medical education in China, China officially promulgated the "Guidelines for the Training of Postgraduate Students in Clinical Medicine" in 2015 and formulated the "four-in-one" training program. The clinical skills and clinical knowledge of professional degree graduates have been developed, but their research capabilities are obviously lacking. Therefore, how to improve the scientific research ability of professional degree graduate students is an urgent problem to be solved in medical graduate education. This article aims to explore some of the problems faced by medical graduate education and their reflections.
\end{abstract}

Keywords: Education; Medicine; Scientific Research; Medical Students; Clinical Courses

\section{Introduction}

Medical graduate students are the main force in the current health industry and their quality and ability directly determine the development of national and social health undertakings. The development of medicine in the 21st century is changing with each passing day. It also puts forward higher requirements for the ability and education of medical graduate students. It should not only pay attention to the cultivation of students' practical work ability, but also pay attention to the cultivation of scientific research ability in order to give full play to their potential and create value. Therefore, the cultivation of scientific research ability has become one of the key training objectives of medical college graduates, especially professional graduate education. With the change of the training objectives of medical graduate education, the education model also needs to be adjusted accordingly. How to transform the traditional education model with emphasis on knowledge transfer to the new education model centered on cultivating scientific research ability is a big challenge for medical colleges and universities [1]. At present, all medical colleges in China have set off a climax of teaching reform. In 2013, in order to improve the quality of medical care in China, the National Health and Family Planning Commission and other seven departments jointly issued the "Guiding Opinions on Establishing a Standardized Training System for Residents", and the reform of the standardization of housing and training began. In 2015, the National Health and Family Planning Commission officially issued the "Guidelines for the Training of Graduate Students in Clinical Medicine" to develop a "four-in-one" training program. The new postgraduate professional degree training model requires 33 months and 3 clinical departments. A degree is awarded after completing the graduation thesis in the month. Such a training program "re-clinical, light scientific research", the professional master's training and resident doctors standardized training boundaries are blurred, but also greatly increased the difficulty of training [2].

Graduate tutors generally believe that according to the existing professional postgraduate "resident physician" training program, although the clinical ability of the students has been improved at the time of graduation, the training of the special science and technology can be caused by the long time taken by the students' clinical rotation. The time of clinical research is too short. Therefore, it is difficult for students to have good clinical skills and clinical research ability of graduates when they graduate. The training of clinical graduate students has become the training of "general practitioners" [3]. The excessive attention of graduate students in science degrees is out of the basic research of clinical studies. When they graduate, they do not have the ability to conduct clinical research. It is difficult to conduct substantive research in short-term basic research. 
Thoughts on the Problems in the Cultivation of Professional Graduate Students' Scientific Research Ability

Strengthen the use of Scientific Research Capabilities in Clinical Work: Clinical practice education is adopted for the teaching of statistics, literature search, scientific research topics and experimental design. This will improve the basic skills of scientific research in medical school students' data collection, papers and project application writing [4]. In clinical teaching, appropriate scientific research knowledge in teaching and teaching lectures can be used to discover the scientific problems of the clinical learning process in time. While cultivating clinical ability, it also strengthens the guidance of scientific research. Guide students to discover problems and solve problems from clinical symptoms, and dare to put forward their own ideas, in order to lay a good foundation in future research and study, not only as a clinician, but as a full-time medical talent.

Construct an Introductory Teaching Course for Clinical Medical Research for Professional Postgraduates: In the course of postgraduate clinical study, in order to ensure the smooth progress of medical tasks in teaching hospitals, the research-related courses are compressed, and the teaching time is adjusted to night and weekend. Such a course arrangement is not conducive to the development of scientific research capabilities. It is necessary to construct scientific research courses that meet the needs of graduate students, cultivate scientific research ideas such as medical students' subject design and project ideas, and explore talent training models that can improve clinical ability and improve scientific research capabilities. Our school is a "first class" clinical medicine major. Combining questionnaire research and repeated discussion, rationally compiling teaching materials, optimizing curriculum and teaching methods, and exploring the most suitable teaching system for clinical medical undergraduate research and development [5]. Through the evaluation and evaluation of the introduction of scientific research courses on the clinical research ability of medical students, and using questionnaires, systematic analysis, optimize curriculum and teaching methods. At the same time, we will also follow up on the scientific research results of the experimental class students after three years of graduation to further adjust the more appropriate education model.

Enhance the Ability of Teachers to Teach, Improve the Theoretical Knowledge of Scientific Research Workers and Achieve the Goal of Teaching and Learning: At present, the tutor plays a great role in the cultivation of scientific research consciousness and scientific research ability of graduate students, but the level of scientific research ability of the tutor itself will have different effects on it [6]. In the current educational environment, it is not enough for the tutor to guide the clinical work. At the same time, it is necessary to guide the students to complete an innovative and credible subject, but also supervise the student certification to complete the research and write the thesis honestly and trustworthy. The department will conduct regular assessments of the tutor's coaching ability, and the tutors with more scientific research ability and scientific research results will have more graduate enrollment quotas, and the unqualified tutors will not be able to recruit graduate students for the time being. Studies have shown that such a mechanism can speed up the coaching ability of the instructor, proved to be an effective competitive mechanism, and bring better opportunities to both students and mentors. It is also in the process of guiding students to grow up. Increased abilities and knowledge updates.

Strengthen the Exchange of Different types of Graduate Students and Learn the Current Specialty and Subspecialty: Development, professional and research graduates focus on different aspects, and personal knowledge and vision are limited. Just as patients need different doctors to cooperate in the treatment process, it is necessary to strengthen the communication and cooperation between clinical graduate students and research graduate students [7]. The thinking mode and knowledge reserve of the two are different. Therefore, different types of graduate students should be encouraged to communicate with each other. The department regularly organizes literature study and reading reports to bring together different students and communicate with each other. Students are required to regularly search for the latest and most popular literature knowledge, organize and report on the study. At the same time, students learn and understand the latest knowledge in the field through discussion and questioning and strengthen the literature search skills. At the same time, they are exposed to different angles. Thinking about the problem.

\section{Conclusion}

In summary, in the process of different development of medical education, medical graduate education and the lack of scientific research and education, which is inconsistent with the current situation of high-quality medical personnel in China, is necessary for the reform of medical education. From students to mentors, from schools to hospitals, multi-faceted efforts and innovations can make China's medical education go further.

\section{References}

1. Yan Jingjing, Zhang Yan (2011) Talking about how to cultivate the innovation ability of medical graduate students. Science and Technology Information (28): 221-223.

2. Cai Jing, Yang Jing (2011) Thinking about the cultivation of master's degree students in clinical medicine degree. Medicine and Philosophy: Humanities and Social Medicine Edition 32(11): 59-604.

3. Ma Jun, Ye Pingping (2014) Analysis of the status quo of clinical medical graduate education. Education in Heilongjiang: Higher Education Research and Evaluation 12: 50-515

4. Li Wen, Luo Chun, Liu Yan (2006) My opinion on humanistic quality education for medical graduate students. China High and other medical education (12): 89-90.

5. Ge Bingchen, Huang Huaxing, Xia Tiansong (2017) Analysis of current status of graduate students in clinical medicine and countermeasures. Journal of Nanjing Medical University (Social Science Edition) 17(1): 6769. 
6. Li Yalin, Zhou Chunyang (2012) Strengthening the construction of postgraduate tutors is the key to ensuring the quality of postgraduate training. Pharmaceutical Education 28(3): 19-23.

ISSN: 2574-1241

DOI: 10.26717/BJSTR.2019.22.003793

Liang Liang. Biomed J Sci \& Tech Res

(C) (P) This work is licensed under Creative

Submission Link: https://biomedres.us/submit-manuscript.php
7. Zou Yang, Wang Daozhen, Zhou Xiaotian (2011) Application of team simulation teaching in clinical skills teaching. China Higher Medical Education (2): 12-13.

$\begin{array}{ll}\text { BIOMEDICAL } & \text { Assets of Publishing with us } \\ \text { RESEARCHES } & \text { - Global archiving of articles } \\ & \text { - Immediate, unrestricted online access } \\ & \text { - Rigorous Peer Review Process } \\ & \text { - Authors Retain Copyrights }\end{array}$

